ecological conditions for survival and may thus have been rare. Our study demonstrates that a simple gradualistic interpretation is not sufficient for an understanding of the actual course of evolution.

I thank Drs. J. Dzik, D. P. Gordon, H. Ristedt, R. Schallreuter, J. Scholz, and P. D. Taylor for their helpful support, discussions, and criticism and I am grateful to B. Peters for drafting Figs. 1 and 2 .

Received September 27, 1990 and January 24, 1991
1. Boardmann, R. S., Cheetham, A. H., Blake, D. B., Utgaard, J., Karklins, O. L., Cook, P. L., Sandberg, P. A., Lutand, G., Wood, T. S., in: Treatise on invertebrate paleontology, Part G (Robinson, R. A., ed.). Boulder and Lawrence: Geol. Soc. Am. and Univ. Kansas Press 1983

2. Pohowsky, R. A., in: Living and Fossil Bryozoa, p. 447 (Larwood, G. P., ed.). $\square 1973$

3. Larwood, G. P., Taylor, P. D., in: Origin of Major Invertebrate Groups, p. 209 (House, M. R., ed.). $\square 1979$

4. Banta, W. C.: Doc. Lab. Géol. Fac. Sci. Lyon 3, 565 (1975)

5. Taylor, P. D.: Palaeontology 33, 19 (1990)

6. Hillmer, G., Schallreuter, R., in:
Bryozoa: Present and Past, p. 113 (Ross, R. P., ed.). West. Wash. Univ. 1987

7. Hillmer, G., in: Fossilien von Sylt II, S. 141 (Hacht, U. v., Hrsg.). $\square 1987$

8. Schallreuter, R., in: Fossil and Recent Ostracods, p. 169 (Bate, R. H., et al., eds.). Chichester: Horwood 1982

9. Taylor, P. D.: Proc. Yorksh. Geol. Soc. 42, 211 (1978)

10. Dzik, J.: Acta Palaeont. Polon. 20, 393 (1975)

11. Dzik, J.: Palaeontology 24, 827 (1981)

12. Jebram, D.: Z. zool. Syst. Evol.-forsch. 11 (4), 1, 275 (1973)

13. Bockele, J. F.: Abstr. Zool. Kolloq. Univ. Hamburg 1979

14. Schallreuter, R.: Abstr. 10th Int. Symp. Ostracoda, p. 53 (1988)

Naturwissenschaften 78, $125-127$ (1991) (C) Springer-Verlag 1991

0028104291001713

\title{
Bioaccumulation, Elimination and Metabolism of Triphenyltin Chloride by Early Life Stages of Minnows Phoxinus phoxinus
}

\author{
K. Fent*, R. Lovas and J. Hunn \\ Swiss Federal Institute for Water Resources and Water Pollution Control \\ (EAWAG/ETH), CH-6047 Kastanienbaum
}

Triphenyltin (TPT) compounds are used as agricultural fungicides in crop protection. They are employed to control potato, celary, sugar beet, coffee, and rice against fungal diseases. Its wide agricultural application could result in the contamination of aquatic systems either by direct application or runoff. TPT is also used as a biocide in antifouling paints on vessels leading to a direct release into the water. Considerable concentrations of this compound were detected in water, biota, and sediments of boat harbors in Lake Lucerne, Switzerland [1].

The degradation of TPT on plant leaves, but also in mammals, proceeds via diphenyltin (DPT) and monophenyltin (MPT) to inorganic tin(IV)

\footnotetext{
* Current address: Woods Hole Oceanographic Institution, Biology Department, Woods Hole, MA, 02543, USA
}

[2]. Photodegradation of aqueous TPT also proceeds via this pathway [3]. As other organotin compounds, TPT is shown to be highly toxic to aquatic life [4]. Early life stages of fish are known to be particularly susceptible to pollutants. For TPT hydroxide an LC50 $(96 \mathrm{~h})$ of $7.1 \mu \mathrm{g} / 1$ was reported in larvae of the fathead minnow [5]. In addition to toxicity studies, information on the bioaccumulation and metabolism of this compound in susceptible aquatic species is needed to assess the ecotoxicological impact.

Previous accumulation experiments in fish were performed using radiolabeled TPT compounds without determination of transformation products [6], or studies have concentrated on adult individuals [7]. Here, we determine for the first time accumulation, depuration, and possible metabolism of TPT in embryos and/or yolk sac fry of a freshwater fish species. Minnows, Phoxinus phoxinus, investigated in this study, are residents of freshwater rivers and lakes which could be contaminated by TPT. The use of unlabeled TPT with appropriate chemical analysis of the parent compound in conjunction with some of its degradation products, DPT and MPT, allowed the determination of the possible transformation. We show that TPT has a high potential for bioaccumulation, because the uptake was rapid, and the elimination and metabolism were only very slow.

Embryos and larvae were exposed at $16{ }^{\circ} \mathrm{C}$ in Petri dishes in a static-renewal procedure to Lake Lucerne water which was spiked with triphenyltin chloride in acetone. In the first experiment, fertilized eggs were exposed for $192 \mathrm{~h}$ to determine the uptake during both embryonic and larval stages. In the second set of experiments, freshly hatched larvae were exposed for $144 \mathrm{~h}$ to determine uptake, and for $192 \mathrm{~h}$ to determine uptake and subsequent elimination. TPT and its metabolites, DPT and MPT, were analyzed by capillary gas chromatography with flame photometric detection (GC-FPD) in experimental water and in whole-body samples. For water analysis the procedure described in [8] was used, employing four internal standards for quantification. In the present study, the method was extended to whole-body analysis of embryos and larvae. After homogenization of embryos or larvae, 
internal standards tripropyltin, mono-, di-, and tripentyltin were spiked with appropriate quantities, and the homogenate was extracted by an ethertropolone solution. After centrifugation the organotin compounds were ethylated, purified by silica gel chromatography and analyzed on a 30-m capillary column. The detection limit for TPT in 100-ml water samples and whole-body samples was 0.06 to 0.09 $\mu \mathrm{g} / 1$ and 0.05 to $0.15 \mu \mathrm{g} / \mathrm{g}$, respectively. All the results in this report refer to the respective phenyltin ion, and whole-body concentrations refer to 30 individuals pooled.

During the daily $24-\mathrm{h}$ exposure, the TPT concentration decreased significantly in the exposure water. Table 1 shows initial TPT concentrations, and concentrations after $24 \mathrm{~h}$ before water renewal. The decrease of initial concentrations after each water renewal was likely due to incorporation into fish, because adsorption to glass walls of Petri dishes is assumed to be minimal. During embryonic/larval exposure, uptake of TPT by Phoxinus phoxinus was biphasic, with different uptake rates before and after hatching (Fig. 1a). During the embryonic phase, uptake was linear reaching $1.02 \mu \mathrm{g} / \mathrm{g}$ after $96 \mathrm{~h}$ at the time before hatching. After hatching, the uptake rate of TPT increased to a level of $4.06 \mu \mathrm{g} / \mathrm{g}$ after a total of 192-h exposure. The biphasic accumulation pattern suggests that the chorion of the eggs has a protecting property by decreasing TPT incorporation into embryos. Compared to TPT, the concentrations of the metabolites, DPT and MPT, were only low. Concentrations of MPT were lower than that of DPT, the latter being in the range of 0.05 and $0.10 \mu \mathrm{g} / \mathrm{g}$ in the embryonic, and between 0.21 and $0.31 \mu \mathrm{g} / \mathrm{g}$ in the larval stage. The increase in DPT concentrations in the larval phase points to a low transforma-
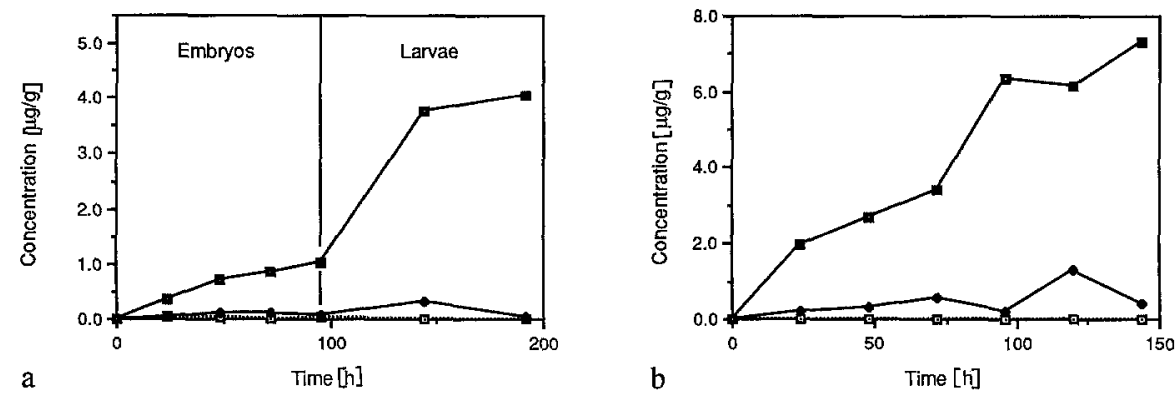

Fig. 1. Uptake and metabolization of TPT by early life stages of Phoxinus phoxinus during embryonic-larval exposure (a), and larval exposure (b). Concentrations of TP'T and its metabolites DPT and MPT are given on a wet weight basis for 30 pooled individuals; ........

tion rate of TPT to DPT in this phase, rather than deriving from impurities of the TPT stock solution.

Freshly hatched larvae exposed to aqueous TPT showed a linear uptake (Fig. $1 \mathrm{~b}$ ). The accumulation of TPT reached $7.33 \mu \mathrm{g} / \mathrm{g}$ by the end of the experiment after $144 \mathrm{~h}$. The rapid accumulation in these larvae is consistent with the uptake rate measured in the larval stage of the first experiment. While MPT was not detectable, DPT concentrations ranged between 0.21 and $1.27 \mu \mathrm{g} / \mathrm{g}$. This is an indication that the transformation of TPT by the yolk sac fry takes place. However, the transformation rate was only minimal. The elimination of TPT was determined by transferring yolk sac fry into clean lake water for $96 \mathrm{~h}$, after bioaccumulation of aqueous TPT for $96 \mathrm{~h}$. Analysis of experimental water revealed that initially there was some contamination after the transfer as shown by measured TPT concentration of $0.29 \mu \mathrm{g} / \mathrm{l}$. As can be seen from the results displayed in Fig. 2, the uptake by the yolk sac fry was linear reaching 3.26 $\mu \mathrm{g} / \mathrm{g}$ after $96 \mathrm{~h}$. No elimination of TPT could be determined after the placement into clean water, indicating that incorporated TPT is eliminated by the yolk sac fry only after long periods of

Table 1. Mean of measured TPT concentrations in experimental water at the beginning $(0 \mathrm{~h})$ and before water renewal $(24 \mathrm{~h})$, and bioconcentration factors BCF (concentration in wet weight/initial water concentration) at the end of the uptake period

\begin{tabular}{lllcc}
\hline Experiment & Exposure & \multicolumn{2}{c}{ Concentration $[\mu \mathrm{g} / \mathrm{l}]$} & \multirow{2}{*}{ BCF } \\
\cline { 3 - 4 } & & $0 \mathrm{~h}$ & $24 \mathrm{~h}$ & \\
\hline I & Embryo/larval, $192 \mathrm{~h}$ & 7.66 & 4.22 & 530 \\
II & Larval, $144 \mathrm{~h}$ & 7.88 & 1.34 & 930 \\
III & Larval, $96 \mathrm{~h}$ & 7.14 & 2.80 & 457 \\
\hline
\end{tabular}

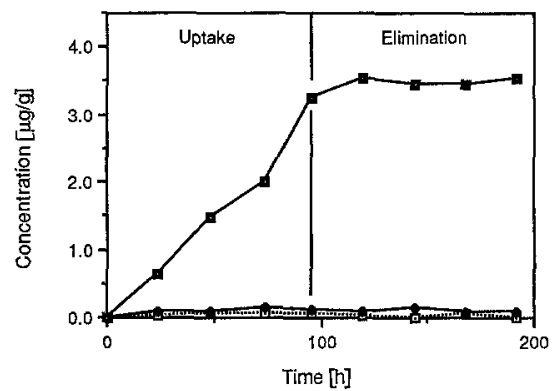

Fig. 2. Uptake and elimination of TPT by yolk sac fry of Phoxinus phoxinus. Concentrations of TPT and its metabolites DPT and MPT are given on a wet weight basis for 30 pooled individuals; $\longrightarrow$ TPT,

time. Concentrations of metabolites DPT and MPT were constantly low during both the uptake and elimination period.

Our experiments show a rapid uptake of TPT from water, while an elimination was absent during the 96-h observation period. There was a linear relationship between the external concentration of TPT and body freights in Phoxinus phoxinus. Whole-body tissue concentrations of TPT did not reach plateaus, which indicates that the bioaccumulation of this compound is even higher in larvae than determined in these experiments. Thus, the calculated bioconcentration factors for TPT (concentration in wet tissue/initial concentration in water) being 530 in the embryonic/larval exposure after $192 \mathrm{~h}$, and 457 and 930 after $96 \mathrm{~h}$ and $144 \mathrm{~h}$, respectively, in the larval exposure, underestimate the real bioconcentration factors (Table 1). In rainbow trout fry, a similar bioconcentration factor of approximately 800 has been determined after a 4-day exposure [6]. 
The TPT elimination from larval tissue was extremely slow, and the metabolites, DPT and MBT, remained very low in tissues during uptake and elimination, suggesting an absence or a very slow catabolism of TPT. Similar as in the early life stages of Phoxinus phoxinus, concentrations of DPT and MPT were also low during 14 days of bioaccumulation and excretion in adult carp [7]. In these fish the metabolite concentrations were relatively higher in the kidneys, liver, and gallbladder than in muscles, suggesting kidneys and liver as being the major sites of metabolism. The lipophilic property of TPT suggests that this compound is mainly accumulated in lipid-rich tissues such as the yolk sac, but also in larval organs such as the liver. TPT has been shown to be quite resistant to mammalian microsomal monooxigenase reactions, but undergoes metabolization by a mechanism which remains to be defined [9]. The findings in Phoxinus phoxinus indicate that TPT has a high potential for bioaccumulation, as the uptake is rapid, and both elimination and metabolization are extremely slow. This behavior of TPT is shared with other organic compounds that have a known high bioaccumulation potential.

Received December 18, 1990
1. Fent, K., Hunn, J.: Environ. Sci. Technol. (in press)

2. Freitag, K. D., Bock, R.: Pestic. Sci. 5, 731 (1974)

3. Sonderquist, C. J., Crosby, D. G.: J. Agric. Food Chem. 28, 111 (1980)

4. Hall, K. W. Jr., Pinkney, A. E.: CRC Crit. Rev. Toxicol. 14, 159 (1985)

5. Jarvinen, A. W., Tanner, D. K., Kline, E. R., Knuth, M. L.: Environ. Pollut. $52,289(1988)$

6. Tas, W. J., Hermens, J. L. M., Van den Berg, M., Seinen, W.: Mar. Environ. Res. 28, 215 (1989)

7. Tsuda, T., Nakanishi, H., Aoki, S., Takebayashi, J.: Wat. Res. 21, 949 (1987)

8. Fent, K., Müller, M. D.: Environ. Sci. Technol. 25, 489 (1991)

9. Kimmel, E. C., Fish, R. H., Casida, J. E.: J. Agric. Food Chem. 25, 1 (1977)
Naturwissenschaften 78, 127-129(1991) (C) Springer-Verlag 1991

$002810429100172 \mathrm{G}$

\section{Light-Induced Release of the Switch Factor During Photophobic Responses of Halobacterium halobium}

W. Marwan and D. Oesterhelt

Max-Planck-Institut für Biochemie, W-8033 Martinsried, FRG

Considerable progress has been made in recent years in the identification of the molecular components of eukaryotic and eubacterial signal transduction chains. Among the best characterized members of signal pathways are the G-proteins in eukaryotes and the sugar and amino acid receptors of eubacteria $[1,2]$. In contrast, close to nothing is known about signal transduction in archaebacteria, the third branch of living matter. Photomovement of Halobacterium halobium $^{1}$ is the only example for an archaebacterial signal chain that is currently studied at the cellular and molecular level. The biochemistry and physiology of these archaebacteria were

1 According to the latest edition of Bergey's Manual now called Halobacterium salinarum good for many surprises already in the past. A further unexpected finding, that fumarate may act as a second messenger, will be presented in this paper. $H$. halobium cells are propelled by a motor-driven flagellar bundle. Swimming of the cells is interrupted by spontaneous motor switching events, reversing the rotational direction of the flagellar motor and, in consequence, the swimming direction of the cell [3]. The random walk resulting from the interference of this motion pattern with Brownian motion of the cells is biased upon excitation of sensory rhodopsin photoreceptor molecules by light stimuli that activate (blue and UV light) or inhibit (green to orange light) the flagellar motor switch (for review see [4, 5].

The photoreceptors, sensory rhodopsin-I and -II (SR-I, SR-II) are linked to the flagellar motor via a branched signal chain that integrates the information released from both receptors $[6,7]$ and works on the basis of chemical messengers [8]. Recently, we showed that the blue-light-induced as well as the spontaneous motor switching requires a membrane-bound lowmolecular-weight compound called switch factor, which is functionally replaceable by fumarate. This switch factor is defined as a component that reintroduces motor switching by somatic complementation of the switch-defective mutant M415.

A halobacterial cell contains about 20000 copies of the switch factor. In disrupted cells, these molecules are almost completely bound to the membrane fraction from which they are released upon heat treatment, presumably by denaturation of a membrane-associated protein that binds the factor [9]. This suggests that the receptors might control the flagellar motor switch through the free cytoplasmic concentration of the switch factor which in turn is determined by reversible dissociation of the factor from the membrane. In this report, we show that the soluble fraction of the switch factor is increased upon light activation of the photoreceptors SR-I and SR-II in vivo. 